\title{
Coastal adaptation to sea level rise along the Nile delta, Egypt
}

\author{
Y. Eldeberky \\ Helwan University, Department of Civil Engineering, \\ Faculty of Engineering, Cairo, Egypt
}

\begin{abstract}
Global warming and climate change processes are expected to raise sea levels. This paper represents a contribution to the efforts of investigating the impact of sea level rise (SLR) on the Nile delta coastal zone and identifies anticipatory and adaptation measures that may be appropriate today in spite of current SLR uncertainties. SLR was calculated by applying the quadratic equation for 10-year intervals using 1980 as the base year. Despite large variation between SLR predictions, the results indicated that SLR is accelerating, with estimated value for the present $(21 \mathrm{st})$ century in the order of $0.6 \mathrm{~m}$, although with a margin of as much as $\pm 0.4 \mathrm{~m}$. Local land subsidence in the Nile delta would exacerbate the impacts of rising seas. It was estimated that with a $1.0 \mathrm{~m}$ SLR, about 4500 square kilometers representing $19 \%$ of the delta area will be submerged and that 6.1 million people will be affected. These potential impacts of SLR would be serious but manageable if appropriate actions are taken. The following adaptation measures to the impact of SLR in the Nile delta coastal zone were identified: maintaining and building coastal protection structures, restoration of sand dunes along the shore, preserving existing wetlands, setting regulations to control development in vulnerable areas, change of land use, relocation of infrastructures in the landward side, and development of comprehensive monitoring and early warning systems.

Keywords: sea level rise, coastal zone, impact assessment, adaptation, the Nile delta.
\end{abstract}

\section{Introduction}

Global warming causes significant threats to the environment, human welfare and socio-economic activities, IPCC [1]. It could cause sea levels to rise by 
expanding ocean water, melting mountain glaciers, and perhaps eventually causing polar glaciers to melt and slide into the oceans. As seas rise, many areas of the coasts will be submerged, with increasing wave attacks. Shoreline retreat will be accelerated. In addition to expected inundation events, severe and frequent storms will cause storm surges on coastal areas, Dasgupta et al. [2]. Fortunately, many of the adverse consequences can be avoided by taking timely measures in anticipation of SLR.

The impacts of SLR will not be globally uniform, because of local variations in topography, wave climate, longshore currents, and storm frequencies. Low gradient coastal landforms most vulnerable to inundation include deltas and estuaries. SLR is expected to threat the Nile delta coastal zone, water resources, agricultural productivity and population (El-Raey [3]). Therefore, it is important to adapt to SLR in the Nile delta coastal zone not because there is expected threats, but because there are opportunities to avoid adverse impacts by acting now. Such consequences can be avoided by implementing measures in anticipation of SLR. This paper examines the implications of future SLR on Nile delta coastal zone and identifies anticipatory and adaptation options that may be appropriate today in spite of current uncertainties.

The paper is arranged as follows. The Nile delta coastal zone is described in section 2. Potential implications of SLR on the Nile delta coast are summarized in section 3. Coastal adaptation options to SLR and their implications, environmentally and socio-economically, are discussed in section 4. Adaptation measures in the Nile delta coastal zone are identified in section 5. Finally, section 6 presents the summary and conclusions.

\section{The Nile delta coastal zone}

The Northern coastal zone of Egypt extends along the Mediterranean coast (995km of coastline). The dominant feature of Egypt's northern coast is the low lying delta of the River Nile, with its large cities, industry, agriculture and tourism. About $25 \%$ of the populations (total 80 million) live in the low elevation coastal zone. Most of these people live in and around a number of very important and highly populated industrial and commercial cities: Alexandria, Port Said, Damietta, and Rosetta, fig. 1. The Nile delta and the Mediterranean coast include $30-40 \%$ of Egypt's agricultural production, and half of Egypt's industrial production. The three main delta lagoons are: Lake Idku, Lake Burullus and Lake Manzala produce over 60\% Egypt's fish catch.

The Nile delta coastal zone is most vulnerable to SLR due to its relatively low elevation and local land subsidence. Most of the $50 \mathrm{~km}$ wide land strip along the coast is less than $2 \mathrm{~m}$ above sea-level and is protected from flooding by a coastal sand belt formed by the sediment discharge of the Rosetta and Damietta branches of the Nile. This protective sand belt is facing rapid erosion, which has been a serious problem since the construction of the Aswan dam. Many studies, [4-6], have shown that the entrapment of sediment in Lake Nasser behind the High Dam, and effects of barrages and river control structures have contributed to erosion along the Nile delta coast. 

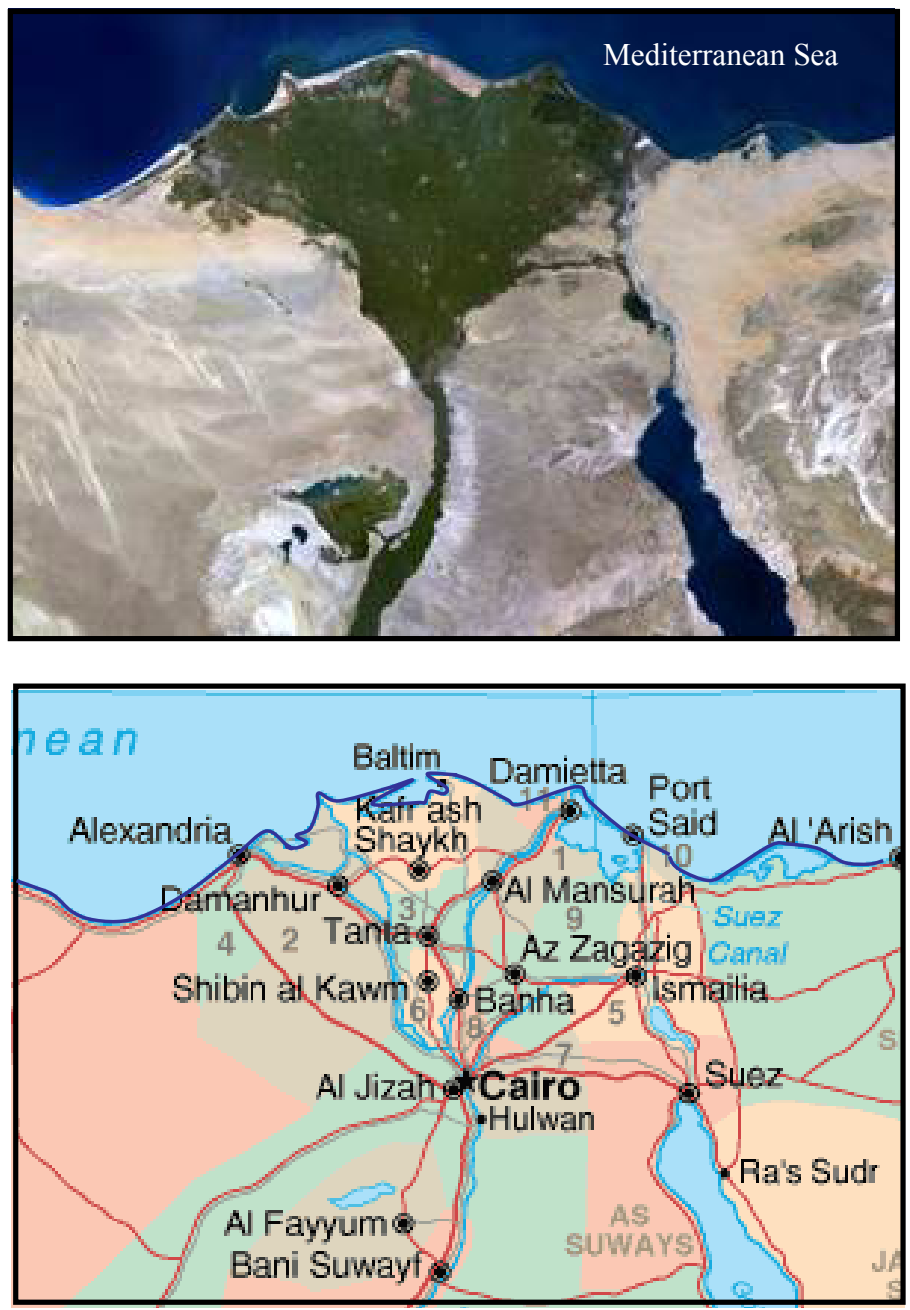

Figure 1: Top: Satellite image of the Nile delta (Source: Google) Bottom: map of the Nile delta and main cities.

\section{Potential impacts of sea level rise on the Nile delta}

The Nile delta is subject to shoreline changes, subsidence, and sea level rise resulting from climate change. The present global trend of SLR receives much attention worldwide. New insights in the earth climate change appear and new models are being developed. There is general agreement that global SLR is accelerating, with estimated values for the present century between 9 and $88 \mathrm{~cm}$ between 1990 and 2100, IPCC [7]. 


\subsection{Prediction of SLR}

Egypt is considered one of the top five countries expected to be mostly impacted with about $1.0 \mathrm{~m}$ SLR in the world (Dasgupta et al. [8]). The accelerated SLR is due to few factors: thermal expansion of the oceans, glacier melting and geological subsidence due to natural or human induced causes (especially in the delta coastal zone).

Local (or relative) changes in sea level depart from the global mean trend due to regional variations in oceanic level change and geological subsidence; it is relative sea-level change that drives impacts and is of primary concern to coastal managers. Relative SLR is expressed as follows:

$$
R(t)=R g(t)+R o(t)+m t
$$

where $R(t)=$ local (or relative) SLR (in meter) in year $t, R g(t)=$ global SLR in year $t, R o(t)=$ regional sea level change in meter induced by oceanic changes in year $t, m=$ vertical land movement, i.e., geological uplift/subsidence, in meter per year, and $t=$ number of years in the future with respect to a base year.

Global SLR scenarios in year $t$ are expressed using a quadratic equation, NRC [9],

$$
\operatorname{Rg}(t)=a t+b t^{2}
$$

where $a=$ incremental SLR in meter per year, and $b=$ acceleration factor $(\mathrm{m} / \text { year })^{2}$. The coefficients $a$ and $b$ can be modified to reflect new scientific information on global SLR (Nicholls and Leatherman [10]).

Global SLR $\operatorname{Rg}(t)$ could be obtained directly from scenario generators that connect simple climate models with sea level models. Given the uncertainties about global SLR, it is important to select a realistic value for the analysis. Therefore, a maximum scenario in which $\operatorname{Rg}(t)$ equals $1.0 \mathrm{~m}$ in year 2100 is quite appropriate for such analysis. Currently, there is insufficient understanding to develop detailed scenarios about regional sea level change. Therefore, the value for $R o(t)$ could be assumed to be zero until more firm information appears.

Values for the vertical land movement $m$, due to geological uplift/subsidence, can be assessed from geological analysis, geodetic surveys, and the analysis of long-term tide gauge measurements (El-Nahry and Doluschitz [11]). It should be noted that the vertical land movement $m$, in eqn. (1), determines the departure of relative SLR from global SLR and that $m$ is assumed to be linear and stays unchanged with respect to time in the future.

Some estimates of vertical land movement indicate that the northern delta region is subsiding at a rate that varies from about $2 \mathrm{~mm} /$ year at Alexandria to about $2.5 \mathrm{~mm} /$ year at Port Said, in addition to tide range about $20 \mathrm{~cm}$.

The computed scenarios of SLR along the Nile delta coast over the present century are shown in fig. 2 . In the calculations, it was assumed that 1980 is the base year. The results show three scenarios representing high, average and low trends of SLR scenarios. The expected average SLR scenario by the end of this century is $0.6 \mathrm{~m}$ with a margin of as much as $\pm 0.4 \mathrm{~m}$. 


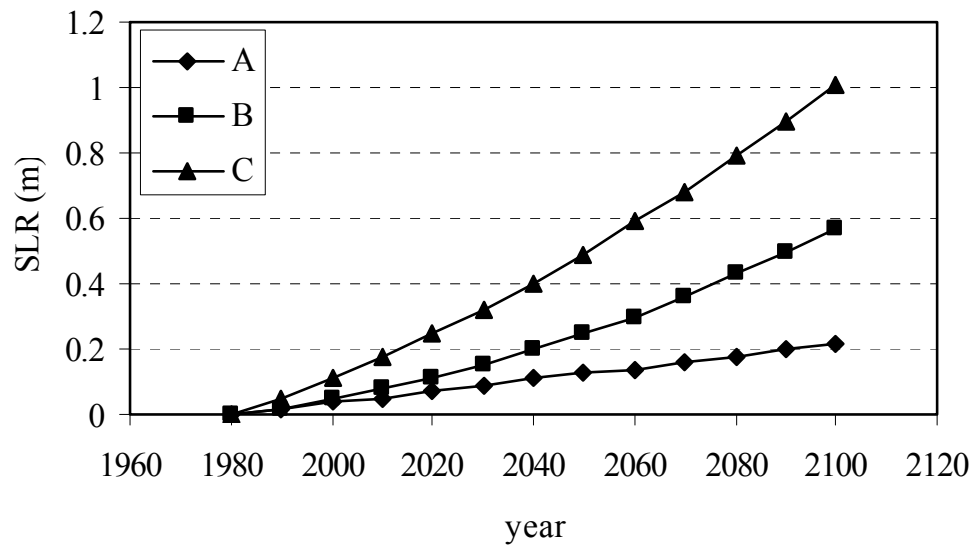

Figure 2: $\quad$ Computed SLR scenarios over the present century (A: high trend; $\mathrm{B}$ : average trend; $\mathrm{C}$ : low trend).

\subsection{Potential land loss due to SLR scenarios}

Various scenarios of SLR will have adverse consequences on the Nile delta. Satellite maps of the Nile delta, fig. 3, show potential land loss due to SLR scenarios. In the $0.5 \mathrm{~m}$ SLR scenario, recreational areas and beach facilities will be inundated. About 1800 square kilometers of cropland, wetland and fish ponds, representing $7.5 \%$ of the total delta area $(23,850.76$ square kilometres), will be submerged. The $1.5 \mathrm{~m}$ SLR scenario will have a catastrophic impact on the Nile delta as coastal zone citizens of the major cities such as Port Said and Alexandria would be displaced. The total loss in area if this scenario occurred would reach 5700 square kilometers representing $24 \%$ of the delta area.

Potential land loss and people affected due to $\operatorname{SLR}$ scenarios $(0.5,1.0$, and $1.5 \mathrm{~m}$ SLR) are summarized in table 1.

Several analyses of the potential impact of SLR on the Nile delta coast have been carried out. These analyses, $[12,13]$, focused on areas of high vulnerability and possible socio-economic impacts. Most vulnerable areas include parts of Alexandria, Port Said, Damietta, and Suez governorates. Potential impacts of SLR on the Nile delta coastal zone are summarized in the following section.

Table 1: $\quad$ Potential land loss and people affected due to SLR scenarios.

\begin{tabular}{|c|c|c|c|}
\hline SLR Scenario & $\begin{array}{c}\text { Land submerged } \\
\text { (square kilometers) }\end{array}$ & $\begin{array}{c}\text { Percentage of } \\
\text { land submerged }\end{array}$ & $\begin{array}{c}\text { No. of People } \\
\text { affected }\end{array}$ \\
\hline $0.5 \mathrm{~m}$ SLR & 1800 & $7.5 \%$ & 4 million \\
\hline $1.0 \mathrm{~m}$ SLR & 4500 & $18.9 \%$ & 6.1 million \\
\hline $1.5 \mathrm{~m}$ SLR & 5700 & $23.9 \%$ & 8 million \\
\hline
\end{tabular}



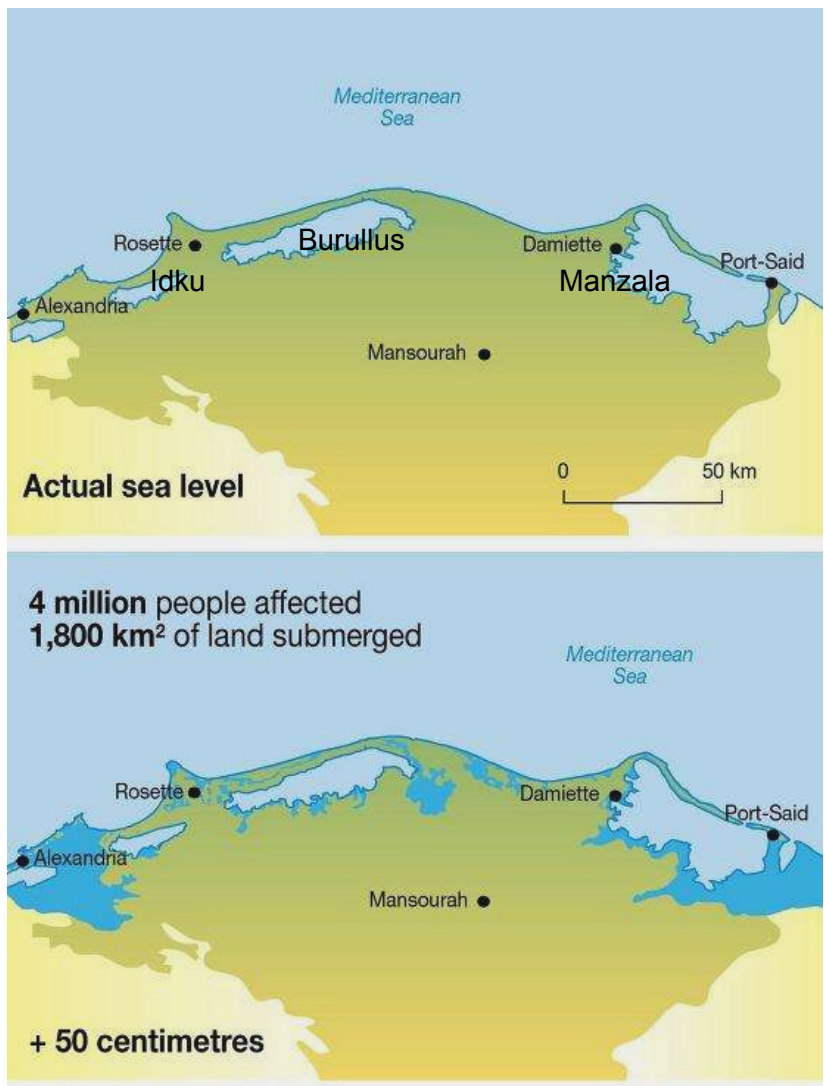

\section{8 million people affected \\ $5,700 \mathrm{~km}^{2}$ of land submerged}

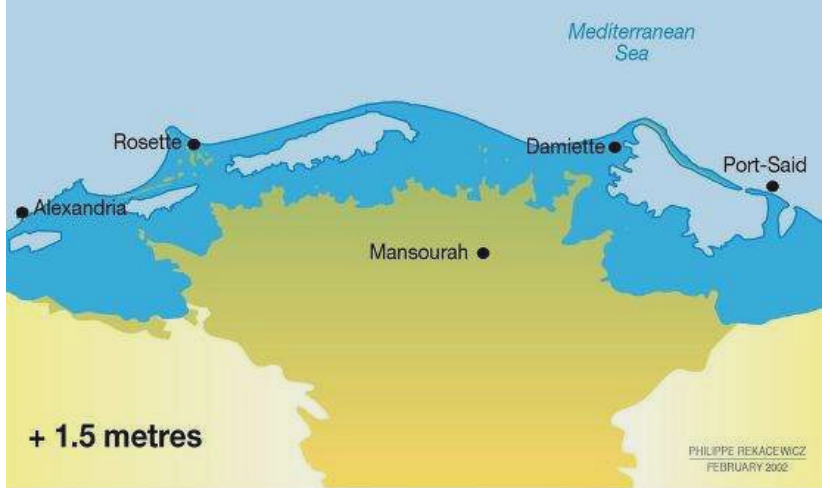

Figure 3: Expected impacts of SLR for two scenarios on the Nile delta. Source: Rekacewicz and Simonett [14]. 


\subsection{The impact of SLR on coastal zone}

The Nile delta shoreline is most vulnerable to SLR due to its relatively low elevation and local land subsidence. In the past, the Nile delta shore was in a dynamic equilibrium between sediment supplied by the river and the transport along the coast. After the construction of the High Aswan dam, sediment input in the delta has been strongly reduced. This resulted in serious shoreline erosion and salt-water intrusion. Currently, the Nile delta is exposed to erosion due to the wave action and the currents of the east Mediterranean gyre. Moreover, the construction of waterways for irrigation and transportation has trapped sediment supply to the Nile delta. This entrapment of sediment is a key contributor to coastal erosion and land loss occurring in the Nile delta and the Nile's two branches, Rosetta and Damietta (e.g. [4-6]). This vulnerability of the coastal zone is now further raised by the threat of accelerated SLR. Rising sea levels are expected to destroy weak parts of the coastal sand belt formed by the sediment discharge of the Rosetta and Damietta branches of the Nile. This protective sand belt is essential for the protection of lakes and the low-lying lands.

In summary, SLR could cause major impacts on the Nile delta coast in terms of: increasing erosion rates due to increasing wave action in the nearshore area; inundation of wetlands and other low-lying lands; increasing risk of flooding; accelerating coastal retreat, including erosion of sand dunes and coastal sand belt, breaching of coastal barriers, and damage of coastal inlets.

\subsection{The impact of SLR on water resources}

The most outstanding impact of SLR on the water resources is that it will increase the occurrence of saline intrusion into coastal aquifers with contamination of groundwater resources in the upper Nile delta. SLR is expected to cause a landward shift of the salt wedge and to increase the rate of saline seepage to the topsoil of the delta. In addition, the salinity in Lake Manzala may increase because of the stronger influence of tidal flows penetrating the lake. ElRaey et al. [15] mentioned that changes in the salinity conditions of the lake may affect its ecology and fisheries and the accelerated SLR will increase the salinity.

\subsection{The impact of SLR on inhabitants}

SLR is expected to affect Egypt coastal population in many ways (Dasgupta et al. [8]). Loss of beaches will reduce the number of tourists in coastal areas, forcing tourism dependent individuals and communities to abandon their settlements and look for jobs elsewhere. This will lead to increased unemployment in these areas.

El-Raey [3] used available land-use data, topographic and socio-economic data to calculate the approximate numbers of people expected to be affected by SLR in the future. Estimation of the socio-economic impact due to loss of land and jobs was performed and results of the impact on population and loss of employment for several affected cities were published. He has also estimated that 
a SLR of $0.5 \mathrm{~m}$ in Alexandria will cause a displacement of almost 1.5 million people and the loss of about 200,000 jobs by the middle of this century.

\subsection{The impact of SLR on agriculture and food resources}

Potential implication of SLR on agricultural areas is significant, mainly because Egyptian cropland in surge zones would increase with SLR and intensified storm surges. The increase of frequency of extreme events will reduce crop yield as well as causing changes in the agricultural distribution of crops. Furthermore, it will negatively affect marginal land and force farmers to abandon them and increase desertification. Expected also socio-economic impacts associated with loss of jobs and increase of unemployment.

\subsection{The impact of SLR on urban areas and infrastructures}

Egypt is ranked the fifth in the world concerning the biggest impact of SLR on the total urban areas (Dasgupta et al. [8]). According to The World Bank report, the impact of SLR and intensified storm surges on specific urban centers of the developing world was examined and the top 10 major cities worldwide that are located in storm-surge zones were listed. Port Said city, Egypt, was found to be the first in the Middle East and North Africa region to be mostly affected.

A one-meter SLR in the Mediterranean will possibly submerge Alexandria. Weakness of the erected sea wall on Alexandria shore is shown in fig. 4. This highlights the deadly exposure of its inhabitants, since storm water drainage infrastructure is often outdated and inadequate in low-income urban centers. Generally, fundamental and low-lying installations in Alexandria and Port Said are endangered by SLR and the recreational tourism beach facilities are at risk.

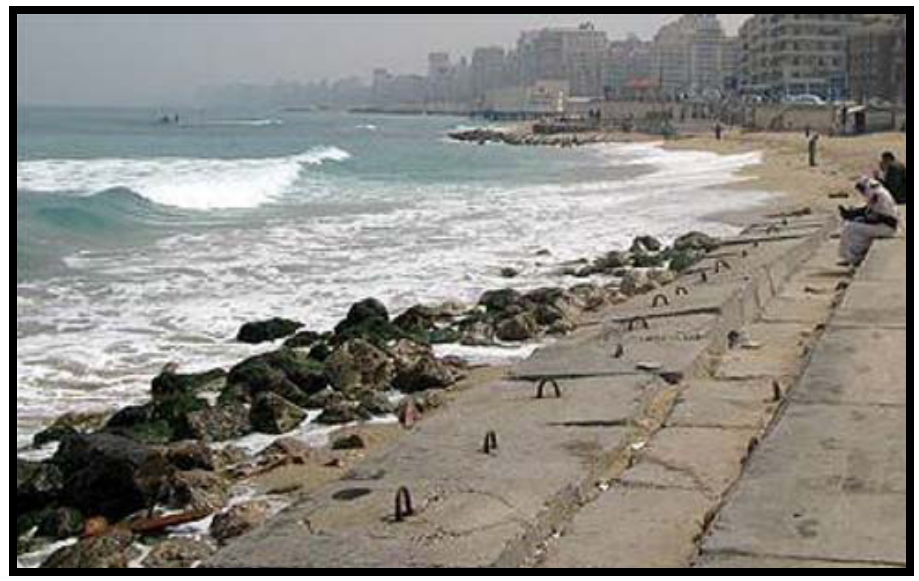

Figure 4: Weakness of the erected sea wall on Alexandria shore. 


\section{Coastal adaptation to sea level rise}

Several measures and adaptation options could be utilized to deal with the SLR impact on the vulnerable coastal segments. This section summarizes responses to SLR and highlights issues that arise with interventions designed to reduce risks to vulnerable coastal areas as a consequence of SLR.

\subsection{Responses to SLR}

In general, the responses required to protect inhabitants and socio-economic developments against SLR in vulnerable coastal zones can be classified into three options: coastline retreat, accommodation and coastal protection, IPCC [16]. The coastline retreat option requires no effort to protect the coastal area against the sea. In the extreme case, an entire coastal area may be abandoned. This choice can be motivated by excessive economic or environmental impacts of the coastal protection option. However, the retreat option is not feasible in highly populated areas with extensive socio-economic activities.

The accommodation option means that people continue to use the coastal area under the threat of accelerated SLR. This option includes emergency flood measures, converting agriculture to fish farming, or growing salt tolerant crops. The coastal protection option includes hard stabilization solutions and soft stabilization solution. The former involves constructing hard structures such as sea walls, breakwaters, and rock revetments to protect the shoreline against the sea. Soft solutions such as sand dunes are used to stabilize the coast so that existing land uses can continue.

Adaptation options are normally site-dependent. Selecting the most effective measures requires analysis to assess available technology options, environmental and socio-economical implications, and long term as well as short term costs and benefits.

\subsection{Environmental implications}

The wetlands of the Nile delta represent about $25 \%$ of the total area of wetlands in the Mediterranean region. Over $60 \%$ of the fish catch of Egypt and many marine species, depend on coastal wetlands (Lake Burullus and Lake Manzala) for their survival. In the retreat option, ecosystems could migrate landward as sea level rises and thus could remain largely intact. Under the protection option, a larger proportion of these ecosystems would be lost. This will be the case especially if coastal protection structures are constructed which will block their landward migration. Coastal structures (such as sea walls) can have a greater impact along coastal areas than soft stabilization solutions (such as dunes and beach nourishment). Hard structures influence beach profiles, sediment deposits and morphology of the coastal zone. Protective coastal structures should be used and designed with great care to avoid negative environmental impacts. Soft stabilization solutions such as beach nourishment retain natural shorelines. 


\subsection{Socio-economic implications}

In case of retreat, relocation of impacted populations may cause political and economical stress of both the displaced people and the host regions. Although the impacts of accommodation and protection would be less stressful, they may still be important. The loss of traditional environments which normally sustain economies could create social instability. Regardless of the response eventually chosen, community participation in the decision making process is important.

The economic impacts of climate change and associated SLR should be included in any response strategy. In the retreat option, coastal landowners would suffer from loss of property, relocation costs and the costs of rebuilding infrastructures. Under the accommodation option, there would be changing property values, increasing damage from storms and costs for modifying infrastructures. Under the protection option, authorities would face the costs for the necessary protective structures. To ensure that coastal development is sustainable, decisions on response strategies should be based on long term as well as short term costs and benefits.

\section{Adaptation measures in the Nile delta coastal zone}

The appropriate adaptation option in certain coastal areas depends on the associated response. If the land for relocation is available; coastline retreat can be implemented through anticipatory land use regulations and building codes. Accommodation may evolve without governmental action, but could be assisted by strengthening flood preparation programs. Coastal protection can be implemented by the Shore Protection Authority. The current measures for coastal zone protection along the Nile delta are unsatisfactory. The coastline response to protective structures should be considered first before implementation.

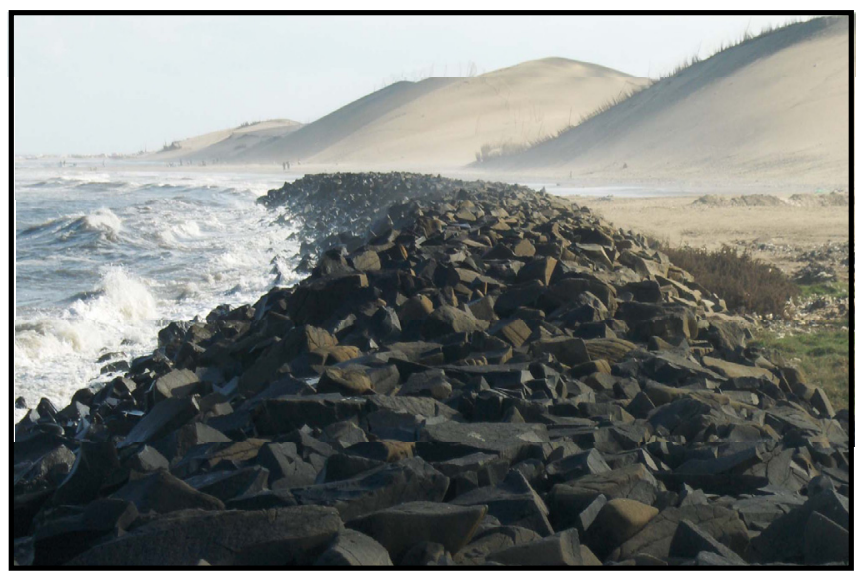

Figure 5: Shoreline at the middle delta coast: protection works and sand dunes. Source: El-Shinnawy [17]. 
Proposed adaptation measures in the Nile delta coastal zone include (but are not limited to):

- Maintaining and building coastal protection structures by the Shore Protection Authority with an emphasis on vulnerable lowlands.

- Restoration and maintenance of sand dunes along the shore, fig. 5, and protective coastal sand belt.

- Preserving existing wetlands (or creating new areas) such as Lake Manzala and Lake Burullus.

- Setting regulations to restrict development in vulnerable areas such as restrictions on set-back line for new developments at low-lying areas.

- Change of land use such as converting agriculture to fish farming or salt tolerant crops.

- Relocation of buildings, roads and other infrastructures in a landward direction.

- Controlling water extraction to minimize saltwater intrusion into ground water in the upper Nile delta.

- Development of comprehensive monitoring program, early warning systems and decision support systems.

\section{Summary and conclusions}

The Nile delta coastal zone is vulnerable to the impacts of SLR and changes in weather patterns from both the environmental and the socio-economic points of view. SLR was calculated by applying the quadratic equation for 10-year intervals using 1980 as the base year. Despite large variation between SLR model predictions, depending on the modeling parameters and scenarios, the results indicated that SLR is accelerating, with estimated value for the present $(21 \mathrm{st})$ century in the order of $0.6 \mathrm{~m}$, although with a margin of as much as $\pm 0.4 \mathrm{~m}$. Local land subsidence in the Nile delta coastal zone would exacerbate the impacts of rising seas. In a $1.0 \mathrm{~m}$ SLR scenario, about 4500 square kilometers of cropland, wetland and fish ponds in the Nile delta coastal zone will be submerged. This area represents about $19 \%$ of the total delta area. Moreover, it is expected that 6.1 million people will be affected. These potential impacts of SLR would be serious but manageable if appropriate actions are taken. Fortunately, many of the adverse consequences can be avoided by taking timely measures in anticipation of SLR.

The current measures for coastal zone protection along the Nile delta coast are unsatisfactory. Proposed adaptation measures in the Nile delta coastal zone include: maintaining coastal protection structures, restoration of sand dunes along the shore, preserving existing wetlands, setting regulations to control development in vulnerable areas, change of land use, relocation of infrastructures in the landward side, development of comprehensive monitoring program and early warning systems, and technical capacity building. Finally, reactive efforts to reduce SLR impacts on vulnerable coastal areas are less effective than responses which are part of integrated coastal zone management (ICZM). 


\section{References}

[1] Intergovernmental Panel on Climate Change (IPCC), Fourth Assessment Report. Climate Change 2007: Synthesis Report. www.ipcc.ch/ipccreports /ar4-syr.htm

[2] Dasgupta, S., Laplante, B., Murray, S., \& Wheeler, D, Sea-Level Rise and Storm Surges: A Comparative Analysis of Impacts in Developing Countries. World Bank Policy Research Working Paper 4901, 2009.

[3] El-Raey, M., Impact of climate change on Egypt, Environmental Software and Services. www.ess.co.at/GAIA/CASES/EGY/impact.html

[4] Inman, D.L., Elwany M.H.S., Khafagy A.A., \& Golik A., Nile Delta profiles and migrating sand blankets. Proceedings of 23th International Coastal Engineering Conference, ed. Billy Edge, Venice, Italy, ASCE, New York, pp 3273-3284, 1992.

[5] Fanos, A.M., The impact of human activities on the erosion and accretion of the Nile Delta coast. J. Coastal Research, 11, pp 821-833, 1995.

[6] Stanley, J.D., \& Warne A.G., Nile Delta in its destructive phase. J. Coastal Research, 14, pp. 794-825, 1998.

[7] Intergovernmental Panel on Climate Change (IPCC), Climate Change 2001: The Scientific Basis. www.ipcc.ch.

[8] Dasgupta, S., Laplante, B., Meisner, C., Wheeler, D., \& Yan, J, The Impact of Sea Level Rise on Developing Countries; A Comparative Analysis. World Bank Policy Research Working Paper 4136, 2007.

[9] National Research Council (NRC), Responding to changes in sea level: engineering implications. National Academy Press, Washington DC, 1987.

[10] Nicholls, R.J, \& Leatherman, S.P., Adapting to sea-level rise: relative sealevel trends to 2100 for the United States. Coast Manage, 24, pp.301-324, 1996.

[11] El-Nahry, A.H. \& Doluschitz, R., Climate change and its impacts on the coastal zone of the Nile delta, Egypt. Environ. Earth Science, 59, pp. 1497$1506,2010$.

[12] El-Raey, M., Nasr, S., Frihy, O., Desouki, S. \& Dewidar, Kh., Potential impacts of accelerated sea level rise on Alexandria governorate, Egypt. J. Coastal Research, special issue 14, 1995.

[13] EL-Raey, M., The cost of coastal vulnerability to climate change. Conference on climate change and coastal cities, beaches and the Delta, Cairo, Egypt, 2009.

[14] Rekacewicz, P., \& Simonett, O., Impact of sea level rise on the Nile delta. www.grida.no/publications/vg/water2/page/3292.aspx

[15] El-Raey, M., Dewidar, Kh, \& El Hattab, M., Adaptation to the impacts of sea level rise in Egypt. Climate Research, 12, pp. 117-128, 1999.

[16] Intergovernmental Panel on Climate Change (IPCC), First Assessment Report: Climate Change 1990. Response Strategies Working Group, www.ipcc.ch.

[17] El-Shinnawy, I.A., Vulnerability assessment and adaptation policies for CC Impacts on the Nile delta coastal zones. www.arab-hdr.org /publications/ahdr//2009/alexandria/pres 